ISSN: 1130-2887 - e-ISSN: 2340-4396

\title{
UN CUARTO DE SIGLO. NOTA DE LA DIRECCIÓN DE ALH
}

América Latina Hoy cumple en 2016 su primer cuarto de siglo de existencia. El número uno de la revista apareció en julio de 1991 bajo el auspicio del Seminario de Estudios Políticos sobre Latinoamérica (SEPLA) de la Facultad de Ciencias Políticas y Sociología de la Universidad Complutense de Madrid, donde se publicó la revista hasta el número nueve, de noviembre de 1994, en que la edición fue conjunta con el Instituto de Estudios de Iberoamérica de la Universidad de Salamanca, circunstancia que se prolongó hasta el número 20, de diciembre de 1998. A partir de entonces la revista ha estado vinculada exclusivamente al Instituto salmantino.

Si en sus primeros momentos la revista tuvo un carácter coral en su confección y desarrollo, entre los números 15 y 45 la dirección recayó en Esther del Campo y Manuel Alcántara, contribuyendo ambos a consolidar la publicación. Sin embargo, fue el trabajo y la dedicación de Flavia Freidenberg, primero como secretaria de redacción -a partir del número 27 de abril de 2001- y luego como directora -desde el referido número 45 de abril de 2007-, los que impulsaron a la revista a las cotas más altas de excelencia. Su comprometida labor hizo posible que esta publicación consiguiera en 2013 el sello de calidad de la Fundación Española para la Ciencia y la Tecnología (FECYT) y fuera indizada en prestigiosas bases de datos bibliográficas de cobertura internacional, fomentando así su visibilidad y relevancia.

Las metas conseguidas durante estos 25 años no hubieran sido posibles sin el esfuerzo y la participación desinteresada de los numerosos becarios, principalmente vinculados al Máster de Estudios Latinoamericanos del Instituto de Iberoamérica y al Máster de Ciencia Política de la Facultad de Derecho, ambos de la Universidad de Salamanca, y a los evaluadores externos provenientes de diferentes instituciones y disciplinas que prestaron generosamente su colaboración.

El presente número constituye un hito en la trayectoria de América Latina Hoy por cuanto que recoge el relevo en la dirección de la misma en Patricia Marenghi, vinculada a la revista desde el número 23 , de diciembre de 1999. Los objetivos para esta nueva etapa que comienza siguen estando centrados en la consolidación de la revista como 
espacio de discusión y difusión de análisis académicos sobre la realidad latinoamericana y sobre el futuro de la región.

Como parte de este nuevo camino que se inicia, la nueva dirección de la revista América Latina Hoy, su Consejo de Redacción y su Consejo Científico quieren agradecer a todos los colaboradores y especialmente a Flavia Freidenberg el trabajo realizado a lo largo de este cuarto de siglo y se comprometen a continuar trabajando con empeño y constancia para que esta etapa sea tan productiva y enriquecedora como lo fue la anterior.

Esther Del Campo, Manuel AlCántara SÁez y Patricia Marenghi 